\title{
Lung cancer health care needs assessment: patients' and informal carers' responses to a national mail questionnaire survey
}

Meinir Krishnasamy Senior Nursing Fellow, Erna Wilkie Research Assistant and Jo Haviland Statistician, Centre for Cancer and Palliative Care Studies, Institute of Cancer Research, Sutton

\begin{abstract}
The objective of this study was to describe patients' and informal carers' perceptions of care received and services offered following a diagnosis of primary lung cancer. We prepared a prospective, national, mail questionnaire survey of 466 patients with a diagnosis of primary lung cancer and a lay carer of their choice. The setting was 24 randomly chosen hospitals throughout the UK, from a range of urban $(n=11)$ and rural settings ( $n=13)$. The majority $(76 \% / 159)$ of responders were recipients of care from cancer units. Two hundred and nine patients (45\%) with primary lung cancer and $70(15 \%)$ lay carers completed questionnaires. The main results that we found were that key areas of unmet need were most apparent during periods away from acute service sectors, with as few as $40 \%$ of patients reporting having received as much help as they needed from community services. The greatest onus of care for patients fell to lay carers, but only $29 \%$ of patients identified their lay carers as having needs in relation to their illness. Where patients received all their diagnostic tests in one hospital they were significantly more likely to wait less time between first seeing their general practitioner $(G P)$ and being told their diagnosis $(P=0.0001)$ than patients who had to attend more than one hospital during their diagnostic work-up period. Fifty per cent of patients reported experiencing some degree of breathlessness even at rest, but only $15 \%$ reported having received any advice on living with it. Less than a quarter $(23 \%)$ of hospital consultants identified anxiety as a key problem for patients with lung cancer, but $66 \%$ of patients identified it as such. Hospital staff largely overlook the needs of informal carers, who derive support from a small, mainly community oriented group of professionals, but accessing help is problematic and is dependent on local resources and a need to be proactive.

Our conclusions are that developments in service provision for patients with lung cancer and their informal carers need to focus on six key areas: development of strategies to encourage patients to present earlier to their GP; ongoing evaluation of rapid diagnostic clinics; development and evaluation of a lung cancer care coordinator role; evaluation of innovations in delivery of nursing care in the community; development of local guidelines to facilitate equitable access to palliative care and social services; and evaluation of supportive strategies targeted at lay carers.
\end{abstract}

Key words: lung cancer; health surveys; needs assessment.

\footnotetext{
Address for correspondence: Meinir Krishnasamy, D Block, Centre for Cancer and Palliative Care Studies, Institute of Cancer Research, Cotswold Road, Sutton, Surrey SM2 5NG, UK. E-mail: meinir@icr.ac.uk
} 
Résumé: L'objectif de cette étude était de décrire les perceptions des patients et des soignants informels, des soins et des services offerts après un diagnostic de cancer du poumon primitif. Nous avons préparé une enquête prospective par questionnaire postal auprès de 466 patients porteurs d'un cancer du poumon primitif et du soignant non professionnel de leur choix. Le cadre en était 24 hôpitaux choisis de façon aléatoire partout dans le ROYAUME-UNI, parmi des établissements $(n=11)$ urbains et ruraux ( $n=13)$. La majorité $(76 \% / 159)$ des répondeurs était les destinataires de soins prodigués dans des unités anti-cancereuses. Deux cents neuf patients (45\%) porteurs de cancer de poumon primitif et $70(15 \%)$ des soignants non professionnels ont rempli un questionnaire. Les résultats principaux que nous avons trouvés étaient que les besoins majeurs insatisfaits étaient moins nombreux au cours des périodes passées hors des services de soins aigus, avec en tout et pour tout seulement $40 \%$ des patients déclarant avoir reçu autant d'aide que nécessaire des services de ville. La responsabilité la plus grande en soins pour les patients revenaient aux soignants non professionnels, mais seulement $29 \%$ de patients ont identifié que leurs soignants avaient des besoins par rapport à leur maladie. Quand les patients ont subi les tests diagnostiques dans le même hopital, il se passait moins de temps entre leur 1 ère visite chez le généraliste et l'annonce du diagnostic ( $P=0.0001$ ) que lorsqu'ils fréquentaient plusieurs hôpitaux pendant la période diagnostique. Cinquante pour cent des patients ont fait l'expérience de difficulté respiratoire même au repos, mais seulement 15\% ont décrété avoir reçu un quelconque conseil les aidant à vivre avec. Moins d'un quart (23\%) des consultants hospitaliers ont identifié l'inquiétude comme un problème clef pour les patients atteints de cancer du poumon, contre $66 \%$ des patients eux-mêmes. Les besoins des soignants informels échappent en grande partie au personnel hospitalier, et ils obtiennent du soutien d'un petit groupe de professionnels, principalement orienté vers la ville, mais l'accès à l'aide est problématique et dépend des ressources locales ainsi que d'un besoin d'être actif.

Nous en concluons que le développement des ressources dans la prise en charge des patients atteints de cancer du poumon doit se concentrer sur six secteurs clefs: développement de stratégies encourageant les patients à se présenter plus tôt à leur GP; évaluation permanente de cliniques permettant des diagnostics rapides; développement et évaluation d'un rôle de coordinateur de soins pour patient atteint de cancer du poumon; évaluation d'innovations dans les pratiques de ville; développement de directives locales pour faciliter un accès équitable à des soins palliatifs et aux services sociaux; et évaluation de stratégies de soutien destinées aux soignants.

Mots-clés: cancer du poumon; enquêtes sanitaires; évaluation des besoins.

\section{Introduction}

Some 43000 new cases of lung cancer are diagnosed in the UK each year, accounting for around 37000 cancer deaths annually. ${ }^{1}$ Despite improvements in survival for other types of cancer, hopes for significant advances in lung cancer survival, and tumour control via new treatments, have not been realized. ${ }^{2}$ The median survival for patients with lung cancer after diagnosis is less than 4 months, with about $80 \%$ of patients dying within 1 year. ${ }^{3}$ In addition, in postindustrial societies, those most affected by the disease are elderly and poor. ${ }^{4}$
Traditionally, lung cancer service provision has been characterized by a lack of coordination, delays in referral by general practitioners (GPs), inappropriate referral patterns, ad hoc treatment rationale, a failure to enter patients into appropriate clinical trials and a lack of palliative care referrals. ${ }^{4-7}$ Patients with lung cancer have been shown to experience greater levels of unmet psychological, social and economic needs than other cancer groups, ${ }^{8}$ and have been reported to be less satisfied with the care received from hospital doctors than are other patients with cancer. ${ }^{9}$ The costs of lung cancer, both in terms of human suffering and economic burden, 
are known to be high, ${ }^{3}$ with the majority of patients experiencing multiple problems including cough, breathlessness, pain, difficulty swallowing, superior vena cava obstruction, and more generalized symptoms such as fatigue, general malaise, weight loss and anorexia., 30,11 These are complex, sometimes intractable problems, which require a combination of medical or pharmacological treatments alongside psychosocial support if they are to be managed effectively. ${ }^{6,11}$ A diagnosis of cancer affects all members of an individual's informal support network. ${ }^{12}$ Lay carers of patients with cancer play a substantial part in the care infrastructure and have been shown to experience considerable physical and psychological needs in relation to their caregiving role. ${ }^{12}$ Nevertheless, little research has been undertaken to establish what services are required to help lay carers cope at minimal cost to their own well-being., 9,13,14

District and local health authorities are now required to assess health needs as a means of obtaining information to plan and purchase costeffective services. ${ }^{15}$ However, a diversity of theoretical frameworks and methodological approaches to needs assessment has compounded the health needs agenda, and insights gained from divergent perspectives of the many disciplines involved have traditionally been rejected across professional groups. However an acceptance of the importance of amassing needs data from multiple perspectives, including patients and their significant others, is becoming increasingly apparent. ${ }^{16,17}$ In response to some of these methodological, care orientated and organizational issues, a national needs assessment survey was undertaken to identify current patterns of UK lung cancer service provision from the perspective of patients, lay, and professional carers.

\section{Methods}

\section{Background}

This study set out to explore perceptions of healthcare need as reported by patients diagnosed with primary lung cancer, a lay carer of their choice and professionals involved in their care, from a random selection of 36 UK hospitals. ${ }^{18}$

Key study aims included:

- to compare professionals' perceptions of needs and problems, as experienced by patients with lung cancer and their families, with patients' and relatives' subjective reports;

- to compare patients' and relatives' subjective perceptions of problems and needs;

- to identify the impact of caring for an individual with lung cancer on family and friends; and

- to promote an awareness of current management strategies for patients with lung cancer.

\section{Accessing the sample}

During 1995, Regional Cancer Registries throughout England and Wales, The Information and Statistics Division in Scotland, the Department of Epidemiology and Public Health in Belfast, and The National Cancer Registry in the Republic of Ireland, were contacted with requests for their most recent, complete, data of registrations of primary lung cancer over the previous 12 months, providing access to numbers of hospital lung cancer registrations throughout the UK and the Republic of Ireland. On receipt of the data requested, two lists were compiled. One list was made up of hospitals designated as non-lung cancer specialist providers, while the other was made up of hospitals identified as providing specialist lung cancer services. Specialist lung cancer services were defined as those where care was available from a respiratory physician, a medical and/or clinical oncologist, a thoracic or cardiothoracic surgeon, and/or palliative care physician as appropriate. ${ }^{18}$ Each hospital was ranked in order of the total number of new patients with lung cancer seen over a complete 12month period. Where data were missing (i.e. hospitals responded but were unable to provide accurate information), hospitals were inserted into the appropriate list at random.

Having drawn up the lists, the number of hospitals to be selected at random was informed by a power equation used to calculate the required sample size $(n=400$ patients $) .{ }^{18}$ Given the acknowledged poor prognosis of patients with lung cancer, ${ }^{1-3}$ a requirement to aim for a sample of at least 1000 patients in order to meet the power equation set was apparent. To ensure that adequate numbers of patients were accessed, while allowing for loss of potential participants through attrition, it became clear that 36 hospitals would need to be randomly selected to the study. By randomly selecting a number between one and 10, every fourth hospital was selected until 18 hospitals had been drawn from each list. Data were eventually 
gathered from participants from 24 hospitals. Reasons for the loss of 12 hospitals to the study included too few hospital consultants agreeing to participate, inadequate IT systems and thus inability to track patients, and, in two instances, lack of ethics committee approval. ${ }^{18}$

The national study began following submissions to each of the 36 hospitals' local ethics committees (which included letters of signed consent by participating consultants to access their patients), and completion of a pilot study to assess the adequacy and acceptability of six questionnaires designed for the project. The study sample included patients, relatives, bereaved relatives, hospital consultants (including respiratory physicians, thoracic or cardiothoracic surgeons, clinical and medical oncologists, palliative care physicians, general physicians with an interest in respiratory medicine and care of the elderly physicians), GPs and Macmillan, Marie Curie, district and practice nurses.

Details of questions asked and responses provided by the professional carers are reported in full elsewhere. ${ }^{19}$

All patients currently registered as receiving treatment or follow-up care in each of the hospitals were eligible to participate. Potential patients for inclusion in the study were identified from hospital consultant records, medical record department databases and checks with GP surgeries.

A member of the research team who sent out a letter detailing the purpose and nature of the work contacted patients. At this stage permission was sought to send out two questionnaires, one to be completed by the patient and one by a lay carer of the patient's choice. On receipt of a reply slip indicating agreement to take part, a questionnaire was mailed to the patient and/or informal carer. Prior to mailing letters of invitation, each patient's GP was telephoned on the day of mailing to ensure that individuals had not died since accessing their contact details from hospital records.

Of the potential sample of 785 patients identified as receiving care or follow-up in the 24 participating hospitals, $319(41 \%)$ were found to have died on checking with GP surgeries, leaving a potential sample of 466 patients. ${ }^{18} \mathrm{~A}$ decision to rely on patients to pass on letters of invitation to informal cares resulted in a poor response rate from this group $(15 \%)$. Methodological lessons learnt in relation to this have been considered elsewhere. ${ }^{18}$

\section{Statistical methods}

All data were entered onto SPSS-PC+. Frequency distributions of the main variables of interest were first carried out in order to determine the number of responses within each category of a particular question on the questionnaire. Variables were then tabulated against each other to investigate associations, and their significance was assessed using the chi-squared test. Where there were small numbers in some cells of the crosstabulations, either categories were combined, or Fisher's exact test was used. Because of the large number of significance tests carried out, associations that were found to be statistically significant from the univariate analysis were entered into multivariate analysis, in order to verify them. In the multivariate analysis, groups of questions related to the same topic were examined for associations, rather than each individual response in turn (as in the univariate analysis). The multivariate analysis was carried out using a general linear model approach. $\mathrm{P}$ values presented below are drawn from multivariate analysis.

\section{Sample characteristics}

Of the 466 patients approached to take part in the survey 209 patients (45\%) returned completed questionnaires. Despite the relatively small numbers of questionnaires returned, and an acknowledgement of the high percentage of patients having undergone surgery (42\%), sample characteristics appear to match UK lung cancer statistics (Table 1). Seventy (15\% of potential sample of 466$)$ lay carers returned completed questionnaires, some of which were returned by bereaved carers or where patients had declined to complete a questionnaire, but had passed on a questionnaire to a lay carer to complete. Demographic details of the sample are given in Tables 1 and 2 .

Fifty-two (26\%) patients had been unwell for less than 1 year. The majority of patients $(79 / 38 \%)$ had been unwell for a period of between 1 and 2 years and 65 patients $(31 \%)$ had been unwell for a period of between 2 and 4 years. Eleven individuals $(5 \%)$ had been unwell for longer than 4 years. 
Table 1 Patient demographics by age, gender, ethnicity and diagnostic group

\begin{tabular}{lcl}
\hline Study group demographics & Number/per cent & National data $^{1}$ \\
\hline Gender $(n=209)$ & $136(65 \%)$ & $28745(69 \%)$ \\
Male & $73(35 \%)$ & $13633(32 \%)$ \\
Female & & \\
Age $(n=209)$ & $6(3 \%)(6$ males) (0 females) & \\
$31-40$ years & $11(5 \%)(10$ males) (1 female) & \\
$41-50$ & $23(11 \%)(18$ males) (5 females) & Increased incidence by age in 55-75 \\
$51-60$ & $86(41 \%)(46$ males) (40 females) & age group \\
$61-70$ & $78(37 \%)(52$ males) (26 females) & \\
$71-80$ & $5(2 \%)(4$ males) (1 females) & \\
$81-90$ & & \\
Ethnicity ( $n=209)$ & 73 white British & \\
Female & 135 white British; \\
Male & 1 Pakistani & \\
& & \\
Diagnostic grouping ( $n=208$ a $)$ & $135(65 \%)(94$ males) (41 females) & $73 \%$ \\
Non-small cell lung cancer (NSCLC) & $59(28 \%)(32$ males) (27 females) & $25 \%$ \\
Small cell lung cancer (SCLC) & $6(3 \%)(5$ males) (1 female) & - \\
Histologically unconfirmed disease & $8(4 \%)$ (5 males) (3 females) & $1 \%$ \\
Mesothelioma &
\end{tabular}

aData were unavailable for one patient.

Table 2 Informal carer demographic details by relationship to patient, age, gender, ethnicity and occupation

\begin{tabular}{|c|c|c|c|c|c|c|}
\hline & \multicolumn{6}{|c|}{ Relationship of lay carer to patient $(n=70)$} \\
\hline & $\begin{array}{l}\text { Wife/partner } \\
(n=35)\end{array}$ & $\begin{array}{l}\text { Husband } \\
(n=9)\end{array}$ & $\begin{array}{l}\text { Daughter } \\
(n=10)\end{array}$ & $\begin{array}{l}\text { Sister } \\
(n=1)\end{array}$ & $\begin{array}{l}\text { Parent } \\
(n=2)\end{array}$ & $\begin{array}{l}\text { Friend } \\
(n=7)\end{array}$ \\
\hline & \multicolumn{6}{|c|}{ Missing data $(n=6)$} \\
\hline Age (mean/range) & $61(36-67)$ & $63(52-72)$ & $42(29-56)$ & 62 & $76(63-89)$ & $61(54-69)$ \\
\hline $\begin{array}{l}\text { Employment status } \\
\text { Full-time } \\
\text { Part-time due to patient's illness } \\
\text { Always worked part-time } \\
\text { Stopped work due to patient's illness } \\
\text { Housewife } \\
\text { Unemployed } \\
\text { Long-standing disability prevents work } \\
\text { Retired }\end{array}$ & $\begin{array}{r}3 \\
2 \\
5 \\
2 \\
8 \\
1 \\
1 \\
13\end{array}$ & $\begin{array}{l}5 \\
\text { Missing data } \\
(n=1)\end{array}$ & $\begin{array}{l}1 \\
\text { Missing dat } \\
(n=1)\end{array}$ & 1 & 2 & $\begin{array}{l}1 \\
1 \\
1 \\
1\end{array}$ \\
\hline $\begin{array}{l}\text { Ethnicity } \\
\text { White British } \\
\text { Black British }\end{array}$ & 35 & 9 & $\begin{array}{l}9 \\
1\end{array}$ & 1 & 2 & 7 \\
\hline
\end{tabular}

\section{Results}

As varying numbers of respondents replied to specific questionnaire items the results presented below reflect totals for the numbers responding to each item.

\section{Events leading to diagnosis}

Patients and their lay carers were asked to describe events leading up to the diagnosis, outlining factors that influenced their presentation to a GP. Few patients reported having any pre-existing lung illness prior to a diagnosis of lung cancer. Nevertheless, almost two-thirds of all patients $(58 / 32 \%)$ who reported visiting their GP because of 'chest symptoms' delayed presentation by between 3 weeks and 3 months (Table 3 ), even where they had experienced up to three (range 1-10; mean 2.6) of the following symptoms: a cough that would not clear, 
Table 3 Patients' and lay carers' reports of time to presenting to a GP

\begin{tabular}{lll}
\hline Time to GP & Patients $(n=205)$ & Lay carers $(n=60)$ \\
\hline Longer than 1 but less than 2 weeks & $55(27 \%)$ & $21(35 \%)$ \\
2 weeks but less than 3 & $55(27 \%)$ & $9(15 \%)$ \\
3 weeks but less than 1 month & $24(12 \%)$ & $7(12 \%)$ \\
1 month but less than 2 & $22(11 \%)$ & $5(8 \%)$ \\
2 months but less than 3 & $12(6 \%)$ & $3(5 \%)$ \\
Unsure & $12(6 \%)$ & $5(8 \%)$ \\
\hline
\end{tabular}

chest infection, feeling generally unwell, feeling weak, feeling unusually tired, losing weight, wheezy/tight chest, shortness of breath, coughing up blood, and a pain in the chest.

When asked to recall what illness they thought their symptoms signified prior to confirmation of diagnosis, patients reported a range of possible options, including:

- cancer, cited by $40 / 20 \%$ of patients;

- chest infection, cited by $38 / 19 \%$;

- asthma, cited by $4 / 2 \%$;

- chronic obstructive airways disease 5/2\%;

- chronic bronchitis, cited 3/2\%;

- TB, cited by $3 / 2 \%$; and

- $33(16 \%)$ patients stated that they did not know what illness they had.

Knowledge of patients' evaluation of symptoms has been shown to be an important factor in addressing delays in presentation to GPs, ${ }^{20}$ and, although no significant association was found between perceptions of what illness the symptoms might signify and time to presentation to GP in this study, patients appeared to act on a number of symptoms experienced $(\mathrm{P}=0.03)$ rather than any conscious self-diagnosis in response to these symptoms.

\section{Referral patterns and time to diagnosis}

Best practice guidelines $3,10,21,22$ state that patients should be referred by their GP for a chest X-ray within 1 week of visiting the surgery; seen in a hospital outpatient clinic and told their diagnosis within 2 weeks of a chest X-ray; and commence treatment within 4-6 weeks of confirmation of diagnosis. Of the patients who participated in this survey, 164 were referred for a chest X-ray or consultation with a hospital consultant following their first GP visit (Figure 1). Having been seen by a GP:

- 18 patients (9\%) waited between 1 and 3 months before being seen in hospital;

- 88 patients $(45 \%)$ were seen at a hospital within 2 weeks of attending their GP;

- the median time to referral for chest X-ray was 2 weeks;

- 30 patients $(16 \%)$ were not referred by their GP for a chest X-ray, but were identified during other

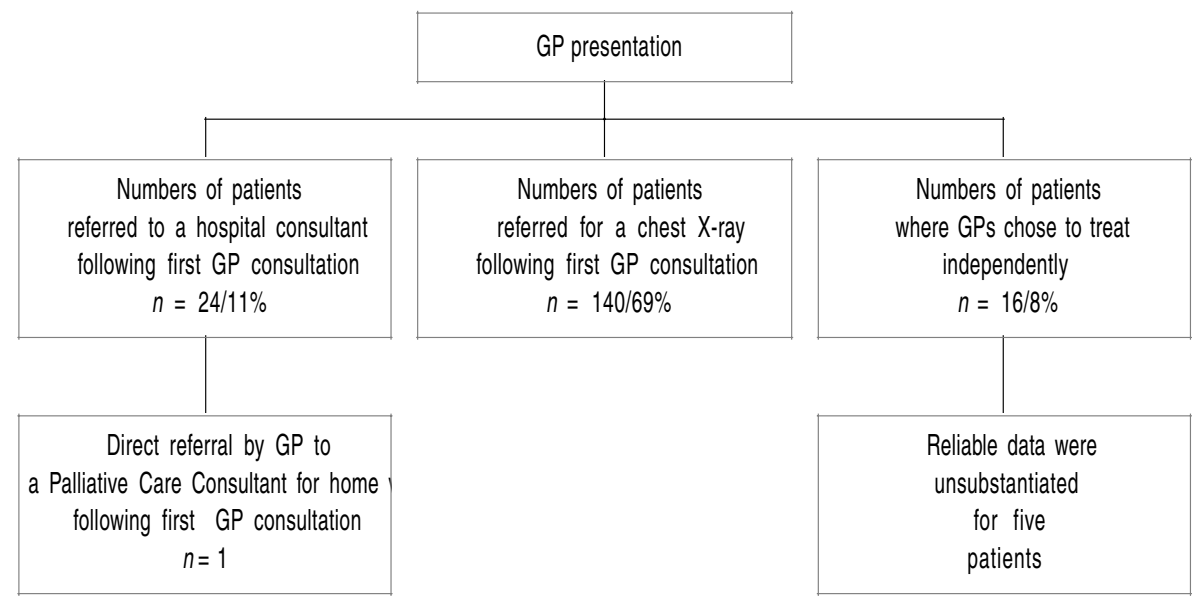

Figure 1 GP referral patterns 
health care encounters, e.g. emergency admissions for other health problems; and

- data were unsubstantiated by hospital notes for a further 13 patients.

All patient and lay carer data relating to referral times and services received were cross-checked with hospital case notes for consistency.

\section{From chest $X$-ray to diagnosis}

Eighty-five patients (43\%) were told their diagnosis by a doctor in an outpatient setting within 3 weeks of first visiting the outpatient clinic. Of these, 16 $(8 \%)$ were given their diagnosis within 1 week and the median time before being told was 3 weeks. However, 79 patients $(40 \%)$ reported having waited longer than 3 weeks to be told their diagnosis and of these 79 patients, over one-half $(47 / 60 \%)$ stated that they had waited longer than 1 month (range: 1-8 months).

Fourteen per cent of patients started treatment within 3 weeks of visiting their GP; the remainder waited between 1 and 8 months. Despite reviewing the case notes of all participating patients it has not been possible to assess, with any degree of reliability, the appropriateness of delays in diagnosing lung cancer where patients waited longer than 3 months. Similar problems in securing reliable data from hospital case notes have been reported elsewhere. ${ }^{23}$

In two instances where patients waited up to 4 months the complexity of securing a definitive diagnosis was evident. However, the majority of delays were associated with undergoing multiple diagnostic tests, compounded by a necessity to travel to different hospitals to undergo diagnostic and staging investigations, and there was significant association between the number of hospitals attended for tests and time before starting treatment $(\mathrm{P}=0.02)$. Twenty per cent of patients had to travel to more than one other hospital to undergo diagnostic tests. Evidence from their case notes suggests that, once referred elsewhere by their original hospital, patients experienced delays due to waiting lists, cancelled appointments, lost referral letters, missing X-rays and blood test results. For the remaining $65 \%$ (132) of patients who received all their tests in one hospital, there was a significant difference in the time they waited between first seeing their GP and being told their diagnosis $(\mathrm{P}=0.001)$.

\section{Information giving and communication}

Of the patients taking part, 148 (71\%) patients had been told their diagnosis by a hospital doctor in an outpatient clinic in comparison with only $33(47 \%)$ informal carers. Twenty-nine (45\%) informal carers had been told the diagnosis by the patient and only just over one-half $(36 / 55 \%)$ had been given the news by a hospital doctor. It is therefore perhaps unsurprising that lay carers complain of a lack of information at time of diagnosis and that they emphasize the importance of repetition of information, and being given adequate opportunity to ask questions. ${ }^{24-26}$

Where patients were given their diagnosis by a hospital doctor, they were significantly more likely to perceive that the information given to them about their illness was clear $(\mathrm{P}=0.001)$ than were patients told by their GP, a nurse or other family member. Data gathered suggest that the source of the diagnosis may be more influential in relation to patients' perceptions of clarity of information given, rather than whether the patient was accompanied when told $(\mathrm{P}=0.001)$. Where patients were given their diagnosis by a hospital doctor, they were significantly more likely to be told that their illness was cancer $(\mathrm{P}=0.009)$ than were patients who were given their diagnosis by other professionals.

Informal carers who described themselves as having received clear or very clear information regarding the diagnosis were significantly more likely to report having received clear information relating to the treatments being offered $(\mathrm{P}<0.001)$. Where the diagnosis was given by a hospital doctor, lay carers were more likely to understand that the illness was lung cancer and to perceive that they had been well prepared for the demands of treatment $(\mathrm{P}<0.001)$.

In response to a question asking patients to identify what they had been told their illness was, less than $60 \%(115 / 58 \%)$ of patients and $50 \%(28 / 45 \%)$ of lay carers stated that they had been told that the illness was cancer or lung cancer. The importance of skilled and sensitive communication of a diagnosis of cancer in relation to patients' satisfaction, treatment adherence and psychological morbidity is well documented, ${ }^{27,28}$ and evidence amassed from a systematic review of effective communication with advanced lung cancer patients ${ }^{29}$ suggested that as many as $90 \%$ of patients would want to know if their illness was cancer. Of the individuals told that their diagnosis was cancer or lung cancer, 64 (55\%) reported having been 
told that they had lung cancer, and of this group, 21 $(33 \%)$ recorded their specific diagnosis, e.g. nonsmall cell lung cancer. For the remainder of the sample, $7(4 \%)$ had been told they had a malignancy, two patients $(1 \%)$ had been told they had a shadow on their lung, but 73 , almost $40 \%$ recalled being told that they had a growth, lump or tumour. It is not possible to determine an individual's actual level of understanding of their diagnosis from the survey data. Nevertheless, $109(53 \%)$ patients and $39(61 \%)$ informal carers felt that they had been given very clear information about their illness. A further 79 (38\%) patients and $15(24 \%)$ lay carers felt that they had received clear information, with only $19(9 \%)$ and five $(8 \%)$ patients and informal carers, respectively, stating that the information had not been clear.

When asked to reflect on the manner in which they were told their diagnosis, $80(39 \%)$ patients reported feeling that the news had been given to them sensitively, while 62 patients $(30 \%)$ reported being told very sensitively. However, 107 (52\%) patients were on their own when told, and of these 107, 42 (39\%) would have preferred to have had a lay carer with them had they been given the opportunity. Some caution is required in interpreting these findings, as 27 patients gave more than one response to the question asking them to describe who was with them when they were told their diagnosis. Sixty-three patients $(31 \%)$ felt that the news of their diagnosis had not been given to them sensitively.

Despite the largely positive reports of perceptions of clarity and sensitivity of communication of diagnosis, only $75(38 \%)$ patients reported having felt able to ask questions, and did ask questions, at the time of diagnosis. Forty-five patients $(23 \%)$ had felt able to ask questions but had not wanted to, while 36 patients $(18 \%)$ stated that they would have liked to have asked questions but were too upset to do so. Numerous factors influencing patients' abilities to ask questions during health care encounters have been identified, e.g. patients' coping styles, physician attitudes and patients and professionals' health care beliefs. ${ }^{27,30}$ When explored against source of information there was little difference in perception of ability to ask questions (irrespective of whether patients had chosen to do so or not; Table 4). Interestingly, patients given their diagnosis by professionals in settings presumed to be disadvantageous to effective communication, such as busy, rushed out-patient settings or GP surgeries, did not report greater feelings of inability to ask questions.

\section{Perceptions of rationale for treatment}

Over one-half of the patients $(106 / 54 \%)$ stated that they were receiving, or had received, curative treatment or treatment that offered a chance of cure. However, data from patients' hospital case notes suggested that treatment was palliative for the majority of the sample, with symptomatic relief, disease containment and prolongation of life documented as the main treatment aims. This apparent disparity may be evidence of some professionals' discomfort with imparting difficult and distressing news, or may indicate a need on patients' behalf to temper realistic awareness with a sense of hope. Ninety-one (42\%) patients described the purpose of their treatment as being to slow their illness and to make them feel better.

Table 4 Source of diagnosis and patients' reported perceptions of ability to ask questions

\begin{tabular}{|c|c|c|c|c|c|}
\hline $\begin{array}{l}\text { Source of } \\
\text { information }\end{array}$ & $\begin{array}{l}\text { Able to ask questions } \\
\text { at time of diagnosis }\end{array}$ & $\begin{array}{l}\text { Able to but } \\
\text { didn't want to }\end{array}$ & $\begin{array}{l}\text { Able to but } \\
\text { too upset }\end{array}$ & $\begin{array}{l}\text { Didn't but a relative } \\
\text { or friend did }\end{array}$ & $\begin{array}{l}\text { Didn't feel } \\
\text { able to }\end{array}$ \\
\hline $\begin{array}{l}\text { Hospital doctor on } \\
\text { the ward }(n=22)\end{array}$ & $16\left(72 \%^{a}\right)$ & $4(18 \%)$ & $1(5 \%)$ & $1(5 \%)$ & 0 \\
\hline $\begin{array}{l}\text { GP in surgery } \\
(n=11)\end{array}$ & $5(45 \%)$ & $3(27 \%)$ & $3(27 \%)$ & 0 & 0 \\
\hline $\begin{array}{l}\text { Nurse on the } \\
\text { ward }(n=2)\end{array}$ & 0 & 0 & 0 & 0 & $2(100 \%)$ \\
\hline Unsure $(n=2)$ & 0 & 0 & $2(100 \%)$ & 0 & 0 \\
\hline
\end{tabular}

aPercentages shown are row percentages. 
Of the treatments most recently received, 64 patients $(31 \%)$ had received them as inpatients, while the majority of $129(62 \%)$ had, or were receiving, care on an outpatient basis, mirroring previously reported patterns of treatment for patients with lung cancer. ${ }^{3,7}$ Radiotherapy was the treatment modality most frequently reported as having been received (56\%), followed by chemotherapy (41\%). Surgery, received by $42 \%$ of the patients with NSCLC in this study, has been described as being appropriate for about $20 \%$ of patients within this diagnostic group. ${ }^{31}$ The high percentage of patients who underwent surgery within this sample may reflect an increasing focus on the numbers and kinds of patients with lung cancer considered eligible for surgery. ${ }^{32}$ These data may also contribute in part, to the quality-of-life scores reported below, as only those patients of good performance status would have been eligible for surgery.

\section{Illness-related problems}

Patients and their lay carers identified numerous problems associated with a diagnosis of lung cancer $^{33}$ (Table 5). Almost one-half of the patients $(98 / 49 \%)$ reported that they had experienced depression and $137(66 \%)$ reported having felt worried or anxious since being told their diagnosis. However, when asked to respond to a question listing a number of possible disease-related problems likely to be experienced by patients with lung cancer, less than one-quarter (24\%) of hospital consultants identified anxiety and none identified depression. ${ }^{19}$
Only $31(15 \%)$ patients reported having received any advice on living with breathlessness, even though $103(50 \%)$ patients reported experiencing some degree of shortness of breath, even at rest. Patients who had received advice on breathing were more likely to say that the information they had received about their treatment was clear and that they felt well prepared for it. Where patients reported feeling well prepared for treatment, they were significantly more likely to feel that they could put up with the side-effects experienced $(\mathrm{P}=0.011)$, or to state that they had experienced no side-effects from treatment $(\mathrm{P}=0.001)$. Only nine $(4 \%)$ patients reported having received any advice on diet, despite almost $50 \%$ of patients reporting having experienced loss of appetite during the previous week. The majority of patients with lung cancer experience considerable weight loss as a consequence of their illness, ${ }^{34}$ and for $30(15 \%)$ patients in this study weight loss had featured as a factor in their decision to present to their GP. Ninety-nine patients (49\%) reported loss of appetite as a problem within the week previous to completing the questionnaire, and of these patients 43 (43\%) remarked that this had affected them quite a bit or very much.

When asked to score their quality of life on a scale of one (very poor) to seven (excellent), 91 (44\%) patients scored five or above, with a further $63(31 \%)$ scoring four, despite the numerous illnessrelated problems identified by patients (Table 5).

Table 5 Patients' and informal carers' reports of illness-related problems - EORTC QLQ-C30 data

\begin{tabular}{lcc}
\hline Key areas of need & Patients $(n=209)$ & Informal carers $(n=70)$ \\
\hline Breathlessness (on walking) & $167(80 \%)$ & $46(65 \%)$ \\
Cough & $146(70 \%)$ & $33(47 \%)$ \\
Pain & $186(89 \%)$ & $28(40 \%)$ \\
Anorexia & $102(49 \%)$ & $47(67 \%)$ \\
Unusual tiredness & $177(85 \%)$ & $82(60 \%)$ \\
Haemoptysis & $23(11 \%)$ & $25(12 \%)$ \\
Anxiety/worry & $138(66 \%)$ & $30(42 \%)$ \\
Depression & $102(49 \%)$ & $26(37 \%)$ \\
Sleeplessness & $123(59 \%)$ & $58(83 \%)$ \\
Social problems (including, financial worries, & $121(58 \%)$ & $0 \%$ \\
impact on family life and reduction in & & \\
social activities) & & $0 \%$ \\
Pleural effusion & & \\
\hline
\end{tabular}


These data may reflect the complexity inherent in accessing meaningful, quantifiable, quality of life data where quality of life instruments are recognized as capturing only aspects of subjective experience. 35,36

\section{Perceptions of sources of support}

When asked whether they had received help from the hospital team at time of diagnosis, 30 patients $(14 \%)$ stated that they had not received any help or advice at this time. Forty-two patients $(21 \%)$ stated that they had received some help but would have liked more, while 133 patients $(65 \%)$ stated that they had received as much help and advice as they had needed from the hospital team at time of diagnosis. When asked whether they had received any help or advice from primary care teams around the time of diagnosis, over twice as many patients $(69 / 34 \%)$ patients stated that they had received no help or advice from primary care sources around this time. Seventy-nine (38\%) patients felt that they had received as much help as they needed from community teams, while $56(27 \%)$ stated that they would have liked more community support. For the patients who participated in this survey, the mainstay of care was delivered in outpatient settings with a mean outpatient follow-up period of 4 months. Not surprisingly patients identified husbands/ wives/partners, children, other relatives, friends and neighbours as their key sources of support (Table 6).

Hospital doctors, GPs, and ward-based nurses were also frequently identified as sources of help. Patients' lack of identification of specialist nurses as a key source of support is alarming. Checks with patients' hospital case notes to try to elicit whether patients were under-reporting referral to Macmillan or other specialist nursing services did not improve this disappointing picture. Participants not considering personal interchange (a major characteristic of specialist nursing practice) as care ${ }^{16}$ may be one explanation for the low reporting of help received. The lack of reliability of hospital case notes as comprehensive records is also acknowledged and the number of patients referred to specialist nurses and palliative care services may be considerably higher.

Only $1 \%$ of patients and $3 \%$ of lay carers identified social workers as being a key source of support. Social services are acknowledged as being targeted at elderly and disabled people with insufficient informal care. ${ }^{25}$ Given that $131(62 \%)$ patients were married (although the majority of people (164/78\%) were aged between 61 and 80 ), the very low reporting of help received from social services may be understood within this context.

Table 6 Patient reported key sources of help and those identified as particularly helpfula

\begin{tabular}{lcc}
\hline Key sources of support identified $(n=209)^{\mathrm{a}}$ & \multicolumn{1}{c}{$\begin{array}{c}\text { Percentage identifying source as being } \\
\text { particularly helpful }^{b}\end{array}$} \\
\hline Hospital doctor & $155(76 \%)$ & $36(21 \%)$ \\
Hospital nurse & $98(48 \%)$ & $2(1 \%)$ \\
Social worker & $7(3 \%)$ & 0 \\
Physiotherapist & $16(8 \%)$ & $83(48 \%)$ \\
Husband/wife/partner & $134(65 \%)$ & $46(26 \%)$ \\
Son/daughter & $113(55 \%)$ & $36(21 \%)$ \\
Friend/neighbour & $92(45 \%)$ & $21(12 \%)$ \\
Other relative & $83(41 \%)$ & $41(24 \%)$ \\
GP & $134(65 \%)$ & $3(2 \%)$ \\
District nurses & $41(20 \%)$ & 0 \\
Specialist nurse (not identified) & $13(6 \%)$ & $11(6 \%)$ \\
Macmillan nurse & $24(12 \%)$ & 0 \\
Marie Curie nurse & $15(7 \%)$ & $16 \%)$ \\
\hline
\end{tabular}

aPatients were invited to identify as many sources as they felt applicable.

bNumbers and percentages are of those identifying source of support. 
Only 21 patients (10\%) had approached voluntary organizations since being diagnosed with lung cancer. Of those individuals, $17(80 \%)$ had found the contact very helpful or quite helpful. Similarly, low utilization of voluntary or support groups has been reported among patients with colorectal cancer ('Colorectal cancer: information needs and preferences for involvement in decision making', Manchester, Macmillan Practice Development Unit, study in progress since 1999), and a lack of information on where and how to access community support services has previously been reported. ${ }^{37}$ Only eight lay carers reported having approached a voluntary or support group.

\section{Sources of support for lay carers}

Partners of patients with cancer have been shown to be reluctant to access professional sources of support, describing themselves as feeling ultimately responsible for coordinating care, ${ }^{12}$ and at times, perceiving outside help as conflicting with a need to preserve independence. ${ }^{38}$ Furthermore, lay carers' perceptions of the burden of caregiving is likely to be influenced by feelings of love and affection, by individual perceptions of purpose in life and awareness of outcome of the disease, ${ }^{39}$ which may be especially pertinent where a patient has lung cancer.

Outpatient doctors $(40 / 66 \%)$, specialist chest physicians (33/56\%) and GPs (41/70\%) were the most frequently cited sources of help by family and friends. However, almost one-half (19/27\%) of those identifying their GPs as a source of support felt that the help received had been only fairly useful or not useful, and as in previous studies GPs were criticized for a lack of unsolicited support and practical help with physical problems. ${ }^{24,40}$ Nevertheless, when compared with patient responses, informal carers rated the help received from GPs, district nurses, and specialist nurses noticeably higher than did patients (Table 7).
When asked to identify sources of nursing support, 19 lay carers (32\%) identified outpatient nurses and a further 19 reported receiving help from a district nurse. However, only $10(15 \%)$ informal carers identified a specialist nurse as a source of support, reflecting findings from previous studies reporting informal carers' perceptions of services received in the year before a patient's death. ${ }^{25,26}$

Although lay carers were most frequently identified by patients as key sources of support, only 61 patients $(29 \%)$ stated that they believed their lay carers had particular needs in relation to their illness. Given the predominance of outpatient care provision, the plethora of problems acknowledged as affecting social activities, family life, financial concerns, and a recognition of significant others as the most helpful sources of support (Table 6), this finding is particularly surprising. However, problems experienced by informal carers in response to the patient's illness were largely psychosocial in nature (outlined below), and it may be therefore that lay carers were able to hide these 'feelings' from patients, eager to protect them from any further stress by minimising their own worries:

- Feeling fearful about the future

$36 / 62 \%$

- Feeling sad

- Feeling low $30 / 52 \%$

- Feeling anxious $29 / 50 \%$

- Feeling restless/unable to relax $27 / 47 \%$

- Feeling angry

- Feeling worried about money $25 / 43 \%$

$13 / 22 \%$

$13 / 22 \%$

- Loss of concentration

Informal carers' reluctance to perceive themselves as having valid needs, which should be met, is anecdotally acknowledged by clinicians and appears to be reinforced by the lay carers who participated in this study. With the exception of $11(18 \%)$, who stated that they did not require any further help, the major-

Table 7 Patients' and informal carers' perceptions of adequacy of professional help received

\begin{tabular}{lcr}
\hline Sources of support & $\begin{array}{c}\text { Percentage of patients identifying } \\
\text { source as being particularly helpfula }\end{array}$ & $\begin{array}{c}\text { Percentage of informal carers } \\
\text { identifying source as being very useful }^{b}\end{array}$ \\
\hline Hospital doctor & $36(21 \%)$ & $31(51 \%)$ \\
Hospital nurse & $16(9 \%)$ & $21(34 \%)$ \\
Social worker & $2(1 \%)$ & $2(3 \%)$ \\
Physiotherapist & 0 & $2(3 \%)$ \\
GP & $41(24 \%)$ & $28(46 \%)$ \\
District nurses & $3(2 \%)$ & $11(18 \%)$ \\
Macmillan nurse & $11(6 \%)$ & $12(20 \%)$ \\
\hline
\end{tabular}

apatients were invited to identify as many sources as they felt applicable.

bNumbers and percentages are of those identifying source of support. 
ity $(49 / 70 \%)$ identified a number of feelings associated with the diagnosis of lung cancer, for which they had not received any support. However, when asked whether they would have liked help to cope with these feelings and concerns, only six (9\%) replied yes. In contrast to patients, few informal carers identified family and friends as key sources of support, despite $26(51 \%)$ stating that they had relied heavily on them since the patients' diagnosis. Only four (7\%) lay carers identified their spouse as a source of support, whereas $134(65 \%)$ patients had identified their spouse/partner as a source of support.

\section{Discussion}

Despite methodological constraints detailed elsewhere, ${ }^{18}$ this paper presents important insights into patients' and lay carers' perceptions of their views of services received in relation to a diagnosis of lung cancer.

\section{Events leading to diagnosis}

Identifying trigger factors that encourage patients to attend their GP promptly is unlikely to significantly improve prognosis but gains in terms of quality of life may be considerable. Helping patients, informal carers and GPs to recognize signs and symptoms that warrant swift and specialist attention is therefore recognized as being central to achieving optimal care for patients and their families, ${ }^{3}$ and the need to undertake research in an attempt to better understand factors affecting early presentation to the GP is gaining increasing recognition. ${ }^{4}$ Further research to evaluate patient preferences, psychological and physiological outcomes, and resource implications in relation to rapid assessment clinics is also needed if developments in diagnostic efficiency are to be translated into overt benefits for patients' and lay carers.

\section{Information giving and communication}

Most patients (136/67\%) in this study reported relying heavily on lay carers for support throughout their illness and treatment. As such, the pattern of diagnostic disclosure to lay carers reflected is worrying. If lay carers are to be helped to support patients they need adequate information provided by skilful and supportive professionals to help them do so. Without this, informal carers will continue to experience feelings of anxiety, loss of control and perceptions of inability to care for and support patients. ${ }^{14,40}$ These feelings may be especially prevalent as patients become very ill and the burden of care falls increasingly to informal carers. ${ }^{25,41,42}$ Lack of information about the disease, associated symptoms and treatment side-effects reflect key areas of unmet need for lay carers of patients with cancer. ${ }^{37}$ Evidence from this and other studies undertaken with lay carers of terminally ill patients in the community suggests that caregivers experience dissatisfaction with information believing it to be too little, too late, or too much and irrelevant, ${ }^{41}$ indicating that communication skills training continues to be a priority area for the provision of effective health care.

\section{Illness-related problems}

Attending to problems of everyday living, such as breathlessness or weight loss, identified as particularly challenging aspects of living with and caring for people with lung cancer in this study, should not be viewed as an additive facet of lung cancer management. Evidence recently reported suggests that patients benefit from supportive strategies targeted at helping them to manage and respond to the physical limitations and psychosocial distress imposed by the complex problems associated with lung cancer. ${ }^{6,42}$ Research drawing on multiprofessional, collaborative approaches to targeting patient centred problems, will provide one way in which some of the health care needs identified here can be addressed within existing resources.

\section{Perceptions of sources of support}

For patients, the most glaring areas of unmet need appear to exist in the periods 'between hospital treatments' when patients are seen at infrequent hospital appointments but prior to regular contact with a hospice or palliative care team. Developments in service provision therefore need to address support services for individuals and their families while away from the hospital setting. Less than one-half of the patients felt that they had received as much care as they needed from the primary care team. This is a cause for concern, as whether care had been provided but not perceived as helpful, or whether in fact no care had been forthcoming, is of little comfort to a patient who feels isolated when at home. 
Of the patients in the study, $136(67 \%)$ agreed or strongly agreed that their illness had made them dependent on family and friends for support. What has previously been largely unacknowledged, however, is the extent to which that dependency incorporates unmet physical symptom management needs, in addition to psychosocial concerns. Hospital services seem to be targeted towards patients' needs, with informal carers left, in the main, to access support from largely community-oriented sources. Data reported from a study of informal carers' satisfaction with services for patients dying of cancer ${ }^{9}$ found that lay carers of patients with respiratory cancers were significantly less likely to report satisfaction with hospital services than were other carer groups. Data from this study suggest that the focus of hospital care on patients, almost to the exclusion of lay carers, may be one possible explanation for this. Developing support strategies, initiated from diagnosis by a dedicated lung cancer team, which help lay carers to anticipate and respond to potential physical and psychosocial problems, should be recognized as an urgent requirement of future care.

Improving access to professions allied to medicine appears to be a key organizational challenge in the development of lung cancer services, where the majority of care is provided in the community and during short stays in hospital. The low reporting of help received from hospice day care settings is particularly difficult to explain. In addition, data from this study suggest that patients with lung cancer and their informal carers are both unaware of the existence of local and national voluntary groups and charities, or do not perceive them as being relevant to their needs. This is clearly an important area for future exploration if patients and their lay carers are to benefit from the considerable expertise available within these organizations.

\section{Conclusions}

Developments in service provision need to focus on six key areas if they are to be responsive to the health care needs of patients with lung cancer and their lay carers:

1) developments of strategies to encourage patients to present earlier to their GP;

2) ongoing evaluation of rapid diagnostic clinics;
3) the development and evaluation of a lung cancer care coordinator role, with responsibility for free flow of information between patients, lay carers and all professional groups involved;

4) evaluation of innovations in delivery of nursing care in the community;

5) development of local guidelines to facilitate prompt and equitable access to a range of professional agencies, with particular attention to palliative care and social services; and

6) evaluation of supportive strategies, initiated from diagnosis, targeting lay carers of patients with lung cancer.

\section{Acknowledgements}

This study was funded by Macmillan Cancer Relief and was undertaken as part of The Macmillan Practice Development Unit's research programme at The Centre for Cancer and Palliative Care Studies, The Institute of Cancer Research, London. Many thanks to Dr Julia Addington-Hall, Department of Palliative Care and Policy (DPCP), King's College London, for her advice throughout the study period and to Dan Altmann, DPCP, for statistical advice and analysis undertaken during the early stages of data analysis.

\section{References}

1 Cancer Research Campaign. Lung cancer and smoking: UK, Factsheet 11. London: Cancer Research Campaign, 1996.

2 Bleehen NM. Lung cancer - still a long road ahead. Br J Cancer 1990; 61: 493-94.

3 NHS Executive. Guidance on commissioning cancer services. Improving outcomes in lung cancer. The manual. National Health Service Executive: DOH/97CC122, 1998.

4 Muers M, Holmes W, Littlewood C. The challenge of improving delivery of lung cancer care. Thorax 1999; 54: 540-43.

5 Hopwood P, Stevens RJ. Symptoms at presentation for treatment in patients with lung cancer: implications for the evaluation of palliative treatment. Br J Cancer 1995; 71: 633-36.

6 Bredin M, Corner J, Krishnasamy M, Plant H, Bailey C, A'Hern R. Multi-centre randomised controlled trial of nursing intervention for breathlessness in patients with lung cancer. Br Med J 1999; 318: 901-904.

7 Pickles H. Ealing, Hammersmith \& Hounslow Health Agency: Lung cancer audit. London: Hammersmith \& Hounslow Health Agency, 1996. 
8 Houts P, Yasko J, Khan B, Schelzel G, Marcon K. Unmet psychological, social and economic needs of persons with cancer in Pennsylvania. Cancer 1986; 58: $2355-61$.

9 Fakhoury W, McCarthy M, Addington-Hall J. The effects of the clinical characteristics of dying cancer patients on informal caregivers' satisfaction with palliative care. Palliat Med 1997; 11: 107-15.

10 Yorkshire Thoracic Group. Recommended standards for improved lung cancer care: the interface between primary care and hospital practice. Recommendations from an interactive regional meeting between General Practitioners and hospital specialists. York: Yorkshire Thoracic Group, 1995.

11 Higginson I, Priest P, McCarthy M. Are bereaved family members a valid proxy for a patient's assessment of dying? Soc Sci Med 1994; 38: 553-57.

12 Oberst M, Thomas SE, Gall KA, Ward SE. Caregiving demands and appraisal of stress among family caregivers. Cancer Nurs 1989; 12: 209-15.

13 Johnson G, Abraham C. The WHO objectives for palliative care. To what extent are we achieving them? Palliat Med 1995; 9: 123-37.

14 Hinton J. Services given and help perceived during home care for terminal cancer. Palliat Med 1996; 10: 125-34.

15 Robinson J, Elkan R. Health needs assessment. London: Churchill Livingstone, 1996.

16 Fitzpatrick R. Health needs assessment, chronic illness and the social sciences. In: Poppay J, Williams G eds. Researching the peoples' health. London: Routledge, 1995: Chap. 10.

17 Cleary PD. The increasing importance of patient surveys. Br Med J 1999; 319: 720-21.

18 Krishnasamy M. Perceptions of health care need in lung cancer. Can prospective surveys provide nationally representative data? Palliat Med 2000; 14: 410-18.

19 Krishnasamy M, Wilkie E. Lung cancer: patients', families' and professionals' perceptions of health care need. A national needs assessment survey. London: Macmillan Practice Development Unit, Centre for Cancer and Palliative Care Studies, Institute of Cancer Research, 1999.

20 Nylenna M, Hjortdahl P. How do patients evaluate cancer related symptoms and signs? A study from general practice. Scand J Prim Health Care 1987; 5: 117-22.

21 British Thoracic Society, Standards of Care Committee. Recommendations to respiratory physicians for managing patients with lung cancer. London: British Thoracic Society, 1996.

22 British Thoracic Society Standards of Care Committee. Lung cancer management survey. London: British Thoracic Society, 1996.
23 Gascoigne P, Mason MD, Roberts E. Factors affecting presentation and delay in patients with testicular cancer. Results of a qualitative study. Psycho-Oncology 1999; 8: 144-54.

24 Field D, McGaughey J. An evaluation of palliative care services for cancer patients in the Southern Health and Social Services Board of Northern Ireland. Palliat Med 1998; 12: 83-97.

25 Addington-Hall J, McCarthy M. Dying from cancer: results of a national population-based investigation. Palliat Med 1995; 9: 295-305.

26 Sykes NP, Pearson SE, Chell S. Quality of care of the terminally ill: the carer's perspective. Palliat Med 1992; 6: 227-36.

27 Takayama T, Yamazaki Y. Relationship between oncology outpatients' perception of physicians' communication styles and patients' anxiety levels. Fourth International Congress of Psycho-Oncology, Hamburg, Germany. Psycho-Oncology 1999; 7: Abst. 25.

28 Almanza-Munoz J, Holland J. A review of literature on breaking bad news in oncology. Abstract of Proffered Papers, 4th International Congress of Psycho-Oncology, Hamburg, Germany. PsychoOncology 1999; 7: Abstract Ref 23.

29 Hearn J, Higginson I. Effective communication with advanced lung cancer patients? A systematic review. Conference abstract, 14th Annual Conference of the British Psychosocial Oncology Society. London: Royal College of Physicians, 1997.

30 Dowsett SM, Saul JL, Butow PN et al. Style versus content: doctor-patients communication in the cancer consultation. Fourth International Congress of Psycho-Oncology, Hamburg, Germany. PsychoOncology 1999; 7: Abst. 26.

31 Ruckdeschel J. Preoperative and postoperative adjunctive therapy for resectable NSCLC. In: Roth J, Cox D, Hong W eds. Lung cancer, 2nd edn. Oxford: Blackwell Science, 1998: 207-16.

32 Talbott D, Smith I. New drugs in lung cancer. In: Thatcher N, Spiro S eds. New perspectives in lung cancer. London: BMJ, 1994: 143-60.

33 Fayers P, Aaronson N, Bjordal K, Sullivan M. EORTC QLQ-30 scoring manual. Brussels: EORTC Quality of Life Study Group on Quality of Life, D/1995/6136/002, 1995.

34 Sarna L, Lindsey AM, Dean H, Brecht ML, McCorkle R. Nutritional intake, weight change, symptom distress, and functional status over time in adults with lung cancer. Oncol Nurs Forum 1993; 29: 481-89.

35 Albrecht G, Devlieger P. The disability paradox: high quality of life against all odds. Soc Sci Med 1999; 48: 977-88.

36 Fitzsimmons D, George S, Payne S, Johnson CD. Differences in perception of quality of life issues between health professionals and patients with pancreatic cancer. Psycho-Oncology 1999; 8: 135-43. 
37 Hileman J, Lackey N, Hassanein R. Identifying the needs of home caregivers of patients with cancer. Oncol Nurs Forum 1992; 19: 771-77.

38 Grande G, Todd CJ, Barclay S. Support needs in the last year of life: patients and carer dilemmas. Palliat Med 1997; 11: 202-208.

39 Folkman S, Chesney MA, Christopher-Richards A. Stress and coping in caregiving partners of men with AIDS. Psychiatr Clin N Am 1995; 17: 35-53.

40 Lynn J, Teno J, Phillips R et al. Perceptions by family members of the dying experience of older seriously ill patients. Ann Intern Med 1997; 126: 97-106.
41 Lecouturier J, Jacoby A, Bradshaw C, Loves T, Eccles M. Lay carers' satisfaction with community palliative care: results of a postal survey. Palliat Med 1999; 13: 275-83.

42 O'Driscoll M, Corner J, Bailey C. The experience of breathlessness in lung cancer. Eur J Cancer Care 1999; 8: 37-43. 